\title{
How Rearing History Affects Alarm-call Responses of Belding's Ground Squirrels (Spermophilus beldingi, Sciuridae)
}

\author{
Jill M. Mateo \& Warren G. Holmes
}

Mateo, J. M. \& Holmes, W. G. 1999: How rearing history affects alarm-call responses of Belding's ground squirrels (Spermophilus beldingi, Sciuridae). Ethology 105, 207-222.

\begin{abstract}
Juvenile, but not adult, Belding's ground squirrels (Spermophilus beldingi) exhibit markedly different responses to alarm calls as a function of their environment. Compared with same-aged, free-living juveniles, captive juveniles (housed in large outdoor enclosures) are more likely to respond to playbacks, to exhibit more exaggerated initial responses (e.g. enter a burrow vs. freeze) and to remain alert longer following playbacks of alarm and non-alarm calls. Two studies were conducted to identify the factors contributing to these response differences. Postemergent rearing environments (such as the opaque enclosure walls that limited visual and auditory stimulation in captivity, or the increased number of conspecifics and natural alarm calls that free-living juveniles experienced) could not account for the majority of response differences between captive and free-living juveniles (Study 1). To determine if the attenuated responses of free-living juveniles were due to foraging pressures, we compared the behaviours of food-provisioned captive juveniles with those of non-provisioned captive juveniles. Although sample sizes were small, no differences were evident in the development or expression of responses as a function of foraging pressure. Next, the development of captive juveniles was compared with that of juveniles reared in the field but housed in captivity after emergence (Study 2). Differences in the response patterns of fieldreared and captive-reared animals matched the differences reported previously, as the responses of field-reared animals observed in captivity mirrored those of freeliving juveniles that remained in the field. Thus, the differences in alarm-call responses originally observed between captive and free-living juveniles are attributed to their pre-emergent, but not post-emergent, rearing histories.

Captive pups experienced levels of auditory, visual, tactile, and olfactory stimulation that were greater than those typically experienced by free-living pups. The increased exposure to conspecific alarm calls may have primed captive pups to respond more often and more intensely to the auditory stimuli they heard as juveniles. Sensitivity to early rearing environments may be adaptive for young ground squirrels if it facilitates the development of antipredator behaviour patterns
\end{abstract}

U. S. Copyright Clearance Center Code Statement: 0179-1613/99/1053-0207\$14.00/0 
that are appropriate for the local predator environment (e.g. openness of habitat, frequency of predators, availability of refuges).

Corresponding author: J. M. Mateo, Department of Psychology, 229 Uris Hall, Cornell University, Ithaca, NY 14853-7601, USA. E-mail: jmm52@cornell.edu

\section{Introduction}

The development and expression of species-typical behaviour patterns, including antipredator responses, are often influenced by the environment in which an animal was reared and by the environment it currently inhabits (e.g. Gottlieb 1981; Turkewitz \& Kenny 1982; Poran \& Coss 1990; Brown et al. 1992; Miller 1994). For example, the rearing environment and the current environment influence how young Belding's ground squirrels (Spermophilus beldingi) respond to alarm calls, predator-elicited vocalizations that may warn conspecifics of danger. When presented with alarm-call and non-alarm-call playbacks, young reared in captivity and then housed as juveniles in outdoor enclosures are more likely to emit an observable response, give a more exaggerated initial reaction, and remain alert longer than are young reared and observed in the field (Mateo \& Holmes 1999). This plasticity may be functional if it allows animals to adjust their antipredator repertoires to their local predator environment (e.g. Lagory 1986; Tulley \& Huntingford 1987; Hauser 1988; Magurran 1990; Mateo 1996a,b). These response differences as a function of environment highlight the need for caution when applying generalizations about behavioural development from laboratory studies to field studies.

However, the response differences we found did give us an opportunity to investigate how early rearing environments might influence the ontogeny of speciestypical behaviour because there were identifiable differences in the environments in which we studied young $S$. beldingi. Any one or a combination of these environmental differences could have been responsible for the differences in alarm-call response behaviour we found in the two groups of juveniles. For example, prior to reaching natal-emergence age when young first leave their natal burrow and appear above ground, captive young experienced much more auditory stimulation than free-living young. After natal emergence, free-living young experienced predators and alarm calls at a higher rate than captive young housed in outdoor enclosures. In this paper we test a variety of hypotheses about the specific rearing experiences that might have mediated these response differences. We then discuss the role of early experiences in the ontogeny of species-typical, alarm-call response behaviour, as well as the possible function of response plasticity in the development of such behaviour.

Belding's ground squirrels are group-living, obligate hibernators that live in alpine and subalpine habitats of the western United States. Mothers rear their young in underground burrows for about 25-28 d, after which their nearly weaned young come above ground for the first time as juveniles (their 'natal emergence'; 
Sherman 1976). Predation on juveniles is frequent, with up to $60 \%$ dying in their first summer (Sherman \& Morton 1984). Slow-moving predators elicit multiplenote trill alarm calls from adults, which in turn cause other $S$. beldingi to post (a bipedal stance). Fast-moving predators elicit short whistles, causing other animals to run to and possibly enter the nearest refuge (Sherman 1977, 1985; Robinson 1980, 1981; Leger et al. 1984; Mateo 1996b). Newly emergent young do not respond to calls in an adult-like manner; discrimination between alarm calls and non-alarm calls appears within $5 \mathrm{~d}$ of natal emergence, whereas response patterns (initial response and response duration) continue to develop until autumnal immergence (Mateo 1996b; Mateo \& Holmes 1997).

\section{Methods}

\section{Animals}

We recorded the responses of individually marked free-living and captive juveniles to daily playbacks of alarm and non-alarm calls between Jun. and Aug. of 1993 and 1994, beginning when young reached natal-emergence age, i.e. about $25 \mathrm{~d}$ old. We observed juveniles during their first $15 \mathrm{~d}$ above ground rather than for $25 \mathrm{~d}$ (as we did in Mateo \& Holmes (1999)), because responses after $15 \mathrm{~d}$ postemergence do not differ markedly for either captive or free-living animals (see also Mateo (1996b)). We grouped our data into two age cohorts for analyses (days 1-5 and days 6-15 post-emergence; Mateo 1996b). We use 'pup' to refer to $<25 \mathrm{~d}$ old, unweaned young still confined to their natal burrow and 'juvenile' for $\geqslant 25 \mathrm{~d}$ old, weaned young that have emerged from their natal burrow.

\section{Study Sites}

\section{Free-living animals}

We studied 65 juvenile $S$. beldingi in a 4 ha meadow in Rock Creek Canyon, Mono Co., CA, USA. We sexed, weighed, and marked juveniles within 1-2 d of their natal emergence (see Mateo (1996b) for details).

\section{Captive animals}

We studied captive juveniles (see sample sizes below) at the Sierra Nevada Aquatic Research Laboratory (SNARL), Mono Co., CA, USA. We housed fieldmated females (collected from four populations within $100 \mathrm{~km}$ of SNARL) in a nursery building at SNARL in which they gave birth and reared their young. Females were in captivity for about $1 \mathrm{wk}$ before parturition (range $=3-10 \mathrm{~d}$ ). We gave the mothers water ad libitum and Purina mouse chow (\#5015; $\approx 20 \mathrm{~g} / \mathrm{d}$ ), which we occasionally supplemented with sunflower seeds and fresh vegetables. We sexed the pups the day after birth and inspected and weighed them every $5 \mathrm{~d}$. For additional details on housing, see Mateo \& Holmes (1997).

When young were 23-24 d old, we transferred them with their mothers to an outdoor enclosure (typically two litters/enclosure, $\approx 4-6$ pups/litter). Each of four 
$9.7 \times 9.7 \times 1.6 \mathrm{~m}$ open-air enclosures included natural vegetation, food and water stations, buried nestboxes, and tunnel systems (see Holmes (1994) for details on the enclosures and Mateo \& Holmes (1997) for details on the tunnel systems). The $1.6 \mathrm{~m}$ high opaque plywood walls of the enclosures limited the animals' visual fields to what they could observe inside the enclosure or see overhead. At the completion of each study, we released juveniles with their mother at the site where we originally trapped the mother.

\section{Playback Stimuli}

We used five categories of auditory playbacks: three types of $S$. beldingi alarm calls (whistle choruses, single whistles, and trills; Robinson 1981; Leger et al. 1984), one $S$. beldingi squeal category, and one house wren, Troglodytes aeodon, song category. For the whistle-chorus playback category, each exemplar was a recording of numerous adults producing single whistles, typically heard when a fast-moving predator is sighted (Sherman 1985; Mateo 1996b). To observe the development of responses to auditory stimuli not associated with predator contexts, we used two additional vocalizations: juvenile squeals (typically emitted during rough play) and wren songs, as control stimuli (see Mateo (1996b) for further details). We also included an 'aerial-object' category to record responses to a single-whistle call paired with a fast-moving visual stimulus (a frisbee flown 2-4 m over the head of an individual 1-2 s after presentation of the alarm call; Mateo 1996b). For some analyses, we grouped the auditory stimuli into alarm calls (whistle chorus, single whistle, and trill) and non-alarm calls (squeal and wren song). We used eight exemplars of each stimulus, selected for their signal amplitude and signal/noise ratio, and recorded each exemplar within a category from a different individual (or individuals for whistle choruses). Recordings were played back at their natural intensities (see Mateo \& Holmes (1999)) through either a Sony TC-D5M or WMD6C cassette player connected to a Nagra DH amplifier-speaker. See Mateo (1996b) and Mateo \& Holmes (1997) for details on auditory recordings and playback-stimulus preparations.

\section{Playback Protocol}

For both free-living and captive juveniles, we presented playbacks daily between 07.00 and $11.00 \mathrm{~h}$ or 15.00 and $18.00 \mathrm{~h}$, beginning when juveniles were about $25 \mathrm{~d}$ old (at natal emergence). We conducted one or two playback sessions per day to each group, with a session consisting of one playback of one exemplar of each of the six playback categories presented in a balanced order. We presented one exemplar about every $15 \mathrm{~min}$, unless we heard a natural alarm call or saw a potential predator during the preceding interval. Both captive and free-living $S$. beldingi continued to respond in a species-typical manner to natural and recorded alarm calls throughout all studies (Mateo 1995), indicating that our playback schedule minimized habituation to the playbacks. We videotaped the animals' responses to playback stimuli from $3 \mathrm{~m}$ high viewing stands, using either a Pana- 
sonic AG 450 VHS camera with a $10 \times$ zoom lens or a Sony CCD-F35 $8 \mathrm{~mm}$ camcorder with a $6 \times$ zoom lens.

For each playback, we began videotaping a randomly selected focal ground squirrel when it was above ground and $\geqslant 1 \mathrm{~m}$ from a burrow. Each individual served as a focal for each playback category at least once and was taped at least every other day. We taped the focal ground squirrel from $15 \mathrm{~s}$ prior to the onset of a stimulus until it resumed a non-alert behaviour, such as feeding or socializing. For captive groups, we fixed a second camcorder on a burrow entrance to videotape the responses of non-focal individuals that were near that burrow or that ran to it. In both environments, the responses of two or three juveniles were thus taped in addition to the focal juvenile, increasing our sample sizes without the need for additional playbacks each day (which could possibly habituate the animals to the playbacks).

\section{Behavioural Response Measures}

We used event-recorder software (ETHOS22; G. Gerstner, University of Michigan) to quantify responses to playbacks, summarizing the frequencies and durations (to the nearest $0.01 \mathrm{~s}$ ) of six alert behaviour patterns (horizontal, slouch, posting, and vertical-stretch postures (defined in Mateo (1996b)), below ground, and running) and four non-alert behaviour patterns (stationary, feeding, grooming, and socializing; Mateo 1995). We then derived three response measures for each individual's response to a playback. 1. 'Responsivity' indicated whether an individual displayed an observable response to a playback, typically presented as the proportion of individuals exhibiting any detectable reaction to a stimulus; 2. 'Initial response' was the animal's first reaction to a playback, categorized as entering a burrow, running to a burrow, posting, or freezing (or raising head); 3. 'Response duration' was the total time an animal exhibited any of the six alert behaviour patterns (above), measured from the beginning of an individual's response (typically concurrent with stimulus onset) until it resumed a non-alert behaviour.

\section{Analyses}

We used an individual's response to each playback as the unit of analysis for each of the three response measures, because between-individual response variation never exceeded within-individual variation (see Mateo (1996b) and Mateo \& Holmes (1999) for a discussion of response independence). However, to minimize potential effects of data independence, we limited the data sets to one presentation of each playback category per individual per age cohort. We found no significant difference in responsivity or response duration by animals originating from different populations (see Captive animals), so we pooled their data when analyses were based on groups of such individuals. Yates' correction for continuity was used for $\chi^{2}$ analyses when $\mathrm{df}=1$ and juvenile age was used as the covariate for all ANCOVAs (response duration is negatively correlated with age; Mateo 1996b). We considered results significant when $\mathrm{p}<0.05$, and present the data as $\overline{\mathrm{x}} \pm \mathrm{SE}$. 


\section{Study 1. Postemergent Experience}

\section{Rationale}

We examined the effect of post-emergent environments on alarm-call response development because the enclosure and field environments inhabited by juveniles differed dramatically. First, levels of visual and auditory stimulation may have differed between the two locations. Free-living Spermophilus spp. often climb promontories to survey their surroundings (Sherman 1977; Leger et al. 1983; MacHutchon \& Harestad 1990; pers. obs.), which increases visual and auditory detection of stimuli (Owings \& Virginia 1978; Brown \& Schwagmeyer 1984). The $1.6 \mathrm{~m}$ high walls of the enclosure may have led to increased vigilance, as the walls prevented detection of approaching predators without providing protective cover (Lagory 1986; Lima 1987; Lazarus \& Symonds 1992). Additionally, the plywood walls may have altered acoustic characteristics of the ongoing auditory cues that ground squirrels rely on to detect predators. Second, the topography of the enclosure ground surface could have provoked the increased reactivity to alarm calls, as juveniles did not have species-typical escape routes or refuges. (This seems unlikely, as the distance to the nearest burrow was quite short and visibility was not hampered by topographic relief. In addition, enhanced visibility would not only expedite direct escape to a burrow, but would prevent predators from ambushing from close range.) Third, because group size was greater in the meadow than in an enclosure, more eyes and ears were available to detect predators in the meadow (e.g. Elgar 1989; Hoogland 1995). Juveniles, particularly older individuals, may adjust their vigilance and responses according to the number of conspecifics nearby. Having fewer ground squirrels in the enclosure (despite their higher density) may have induced greater vigilance in captive juveniles (e.g. Mateo \& Holmes 1999). Finally, the free-living ground squirrels probably heard more alarm calls and saw more potential predators (other than humans) than captive individuals (although we did not systematically quantify the frequency of alarm calls or predator sightings at either location).

\section{Design}

To begin to address the effect of the post-emergent environment on alarm-call response development, we compared two groups, both of which were composed of field-reared juveniles from one population. We live trapped one group at natal emergence and transferred it to an enclosure ('captive-housed', not provisioned; $\mathrm{n}=8$ juveniles from two litters and their mothers) while the other group of juveniles remained in the field ('field-housed'; $n=64$ juveniles from 13 litters). Thus, the groups' pre-emergent histories were similar (general nutrition, natal-emergence weights, and local predator conditions, as well as levels of stimulation in their natal burrows; Daly 1973), but their post-emergent experiences differed (field vs. enclosure; see Table 1). Note that our design does not differentiate between possible effects due to the post-emergent rearing environment and those due to the testing environment. Nevertheless, if the differences between the enclosure and the field 
Table 1: Description of animals observed

\begin{tabular}{|c|c|c|c|c|}
\hline Group & $\begin{array}{c}\text { Pre- } \\
\text { emergence }\end{array}$ & $\begin{array}{c}\text { Post- } \\
\text { emergence }\end{array}$ & $\begin{array}{l}\text { Emergence } \\
\text { weight*广 }\end{array}$ & $\begin{array}{c}\text { Dispersal weight } \\
\text { (age) } \dagger\end{array}$ \\
\hline \multicolumn{5}{|c|}{ Study 1 -Post-emergent experience } \\
\hline Field-housed & field & field & $\begin{array}{c}50.2 \pm 0.8 \mathrm{~g} \\
\mathrm{n}=64^{a}\end{array}$ & $\begin{array}{l}133.7 \pm 4.6 \mathrm{~g} \\
\mathrm{n}=23^{b}(48 \mathrm{~d})\end{array}$ \\
\hline Captive-housed & field & enclosure & $\begin{aligned} 52.3 & \pm 3.6 \mathrm{~g} \\
\mathrm{n} & =8^{a}\end{aligned}$ & $\begin{array}{l}83.8 \pm 3.0 \mathrm{~g} \\
\mathrm{n}=8^{b}(43 \mathrm{~d})\end{array}$ \\
\hline \multicolumn{5}{|c|}{ Study 2 -Pre-emergent experience } \\
\hline Field-reared & field & enclosure & $\begin{array}{c}52.9 \pm 2.7 \mathrm{~g} \\
\mathrm{n}=11^{c}\end{array}$ & $\begin{array}{c}108.27 \pm 14.1 \mathrm{~g} \\
\mathrm{n}=11^{d}(50 \mathrm{~d})\end{array}$ \\
\hline Captive-reared & nursery & enclosure & $\begin{array}{c}34.3 \pm 2.0 \mathrm{~g} \\
\mathrm{n}=19^{\mathrm{c}}\end{array}$ & $\begin{array}{c}162.6 \pm 4.6 \mathrm{~g} \\
\mathrm{n}=24^{\mathrm{d}}(49 \mathrm{~d})\end{array}$ \\
\hline
\end{tabular}

$* \approx 25-27 \mathrm{~d}$ of age; $\dagger \overline{\mathrm{x}} \pm \mathrm{SE} .{ }^{\mathrm{a}} \mathrm{t}=0.79 ; \mathrm{df}=70 ; \mathrm{p}>0.05 ;{ }^{\mathrm{b}} \mathrm{t}=6.23 ; \mathrm{df}=29 ; \mathrm{p}<0.001$; ${ }^{c} \mathrm{t}=5.57 ; \mathrm{df}=28 ; \mathrm{p}<0.001 ;{ }^{\mathrm{d}} \mathrm{t}=4.69 ; \mathrm{df}=33 ; \mathrm{p}>0.001$.

environments (e.g. auditory and visual stimulation, refuges, group size) accounted for the discrepant alarm-call responses of juveniles observed in each environment (Mateo \& Holmes 1999), then we expected the captive-housed juveniles (that were reared in the field) to be more responsive to playbacks than field-housed young.

\section{Results}

Overall, we found no difference in responsivity between the two groups $\left(\chi^{2}=2.82 ; \mathrm{df}=1\right.$; ns). Captive-housed juveniles were more likely to show some kind of observable response to alarm calls than field-housed juveniles (Table 2), yet this difference disappeared when the data were analysed by age cohort (days

Table 2: Summary of responses to alarm-call and non-alarm-call playbacks by captivehoused and field-housed juveniles (Study 1)

\begin{tabular}{|llcc|}
\hline Measure & Group & Alarm calls & Nonalarm calls \\
\hline Responsivity & captive-housed & $87 / 91(95.6 \%)$ & $12 / 45(26.7 \%)$ \\
$(\mathrm{n}$ responding*, \%) & field-housed & $136 / 163(83.4 \%)$ & $23 / 80(28.8 \%)$ \\
& $\chi^{2}$ & $6.97, \mathrm{p}<0.01$ & $0.002, \mathrm{~ns}$ \\
Response duration & captive-housed & $32.0 \pm 1.7 \mathrm{~s}$ & $17.1 \pm 6.3 \mathrm{~s}$ \\
$(\overline{\mathrm{x}} \pm \mathrm{SE})$ & field-housed & $39.2 \pm 3.7 \mathrm{~s}$ & $23.3 \pm 5.3 \mathrm{~s}$ \\
& F (df) & $3.18(1,294), \mathrm{ns}$ & $0.41(1,32), \mathrm{ns}$ \\
\hline
\end{tabular}

$*_{n}=$ number of juveniles responding out of number that could have responded. SE, standard error. 
1-5: $\chi^{2}=1.31$ and days $6-15: \chi^{2}=2.54$; both $\mathrm{df}=1$ and $\mathrm{ns}$ ). There was no significant difference in response duration following playbacks of alarm or nonalarm calls (Table 2). However, initial responses did differ significantly $\left(\chi^{2}=58.98\right.$; df $=3 ; \mathrm{p}<0.001)$, with the field-housed ground squirrels more likely to post $\left(32.9 \%\right.$ of 158 initial responses; partitioned $\left.\chi^{2}=7.73 ; \mathrm{df}=1 ; \mathrm{p}<0.01\right)$ and the captive-housed juveniles more likely to run to a burrow (64.2\% of 151 responses) than any other response type (partitioned $\chi^{2}=47.40 ; \mathrm{df}=1 ; \mathrm{p}<0.001$ ). We found no difference in responses to aerial-object playbacks (responsivity: Fisher's exact test, $\mathrm{p}>0.50$; response duration: ANCOVA $\mathrm{F}=2.59$; $\mathrm{df}=1,51 ; \mathrm{ns})$.

\section{Discussion}

We did not find evidence that differences in the post-emergent environments of free-living and captive juveniles explained the differences reported previously (Mateo \& Holmes 1999) in the development of alarm-call response behaviour. Post-emergent housing had no consistent effect on the development of responsivity to auditory stimuli (when analysed by age cohort, as responsivity changes with age; Mateo 1996b) or response duration, but did affect initial responses to playbacks. However, this difference in initial reactions may be attributed to the closer proximity of burrows in an enclosure compared with in the field, although we did not record animal-burrow distances at either location. The response repertoires of captive- and field-housed juveniles were similar to those of field-reared mothers observed either in captivity or in the field (see Mateo \& Holmes (1999)), such that juveniles' post-emergent environments only had a consistent effect on their initial responses to playbacks.

Captive ground squirrels in Mateo \& Holmes (1999) were provided with mouse chow ad libitum, besides the vegetation in the enclosure, and juveniles subsequently weighed more around the age of dispersal than their free-living counterparts. Ground squirrels must accumulate sufficient body fat to survive a winter (Murie \& Boag 1984; more than $60 \%$ of $S$. beldingi juveniles die during their first winter; Sherman \& Morton 1984), and juveniles increase their foraging efforts as the summer proceeds (Morton 1975). Because captive ground squirrels, provided with ad libitum food, did not have to trade-off time between foraging and vigilance, they may have been able to 'afford' heightened responses to playbacks, including spending more time alert (and thus not eating) and expending more energy in their responses, such as running to a burrow rather than posting in place (Holmes 1984; Lima \& Dill 1990; Bachman 1993). To examine a possible provisioning effect, we conducted a pilot study with two groups of field-reared juveniles both of which were housed in enclosures after emergence. We gave one group ( $n=3$ juveniles) mouse chow ad libitum, while the other group $(n=8)$ foraged on the enclosure's vegetation (Carex spp.) and scattered sunflower seeds. We found that non-provisioned juveniles were more responsive to alarm-call playbacks than provisioned juveniles, which is opposite to what one would expect based on a trade-off between foraging and vigilance efforts. Thus, although our provisioned group was small in numbers, our pilot results suggest that differences 
in foraging pressure, which were indirectly demonstrated as differences in body weights, do not explain the disparities in alarm-call responses between captive and free-living juveniles (Mateo \& Holmes 1999).

The data from Study 1 (Table 2) suggest that the differences between the two environments (e.g. the opaque walls of the enclosures, the number of conspecifics, features of the microhabitat, and foraging pressure) cannot fully explain the alarmcall response differences between captive- and field-reared juveniles that were reported in Mateo \& Holmes (1999). We are not suggesting, however, that other, specific experiences after emergence, such as the frequency of predator attacks in different environments, will not influence the development of responses to playbacks (e.g. Mateo 1995).

\section{Study 2. Pre-emergent Experience}

\section{Rationale}

Given the results of Study 1, we next sought to determine whether response differences between captive- and field-reared juveniles (Mateo \& Holmes 1999) could be explained by differences in the pre-emergent environments experienced by developing young. Individuals that were born and reared in the nursery building (which simultaneously housed many litters) experienced frequent stimulation compared with free-living animals. For instance, captive mothers and older juveniles vocalized frequently, and we handled pups repeatedly to monitor their growth (see also Daly 1973). Thus, the pre-emergent environments of nursery- and field-reared pups differed in several ways.

\section{Design}

To delineate the effects of pre-emergent histories, we compared one S. beldingi group that was born and reared in the field ('field-reared'; $n=11$ juveniles from three litters and their mothers, collected on the day of natal emergence) with another group that was born and reared in the nursery ('captive-reared'; $n=24$ juveniles from five litters and their mothers). We placed both groups in separate enclosures at natal emergence (around $25 \mathrm{~d}$ old) and recorded their alarm-call responses for $15 \mathrm{~d}$ (body weights were similar during the post-emergent period; Table 1). If the differences originally observed between captive and free-living juveniles in Mateo \& Holmes (1999) were due to their disparate experiences prior to emergence, then we expected captive-reared juveniles to be more responsive to playbacks and to remain alert longer, compared with field-reared individuals, even though both groups inhabited and were tested in enclosures after emergence.

\section{Results}

When we presented playbacks to enclosure-housed animals, field-reared juveniles were less responsive to alarm calls $\left(\chi^{2}=4.10 ; \mathrm{df}=1 ; \mathrm{p}<0.05\right)$ and, to a lesser extent, non-alarm calls $\left(\chi^{2}=2.93\right.$; $\left.\mathrm{df}=1 ; \mathrm{p}<0.09\right)$ than captive-reared 
young (Fig. 1a). The difference in responsivity to alarm calls developed across the age cohorts (days 1-5: $\chi^{2}=0.15 ; \mathrm{df}=1 ; \mathrm{ns}$ and days $6-15: \chi^{2}=4.25 ; \mathrm{df}=1$; $\mathrm{p}<0.05)$. Initial responses also differed between the groups $\left(\chi^{2}=25.26 ; \mathrm{df}=3\right.$; $\mathrm{p}<0.001)$, as captive-reared young were more likely to enter a burrow than fieldreared juveniles (partitioned $\chi^{2}=23.22 ; \mathrm{df}=1 ; \mathrm{p}<0.001 ;$ Fig. 1b). Captive-reared
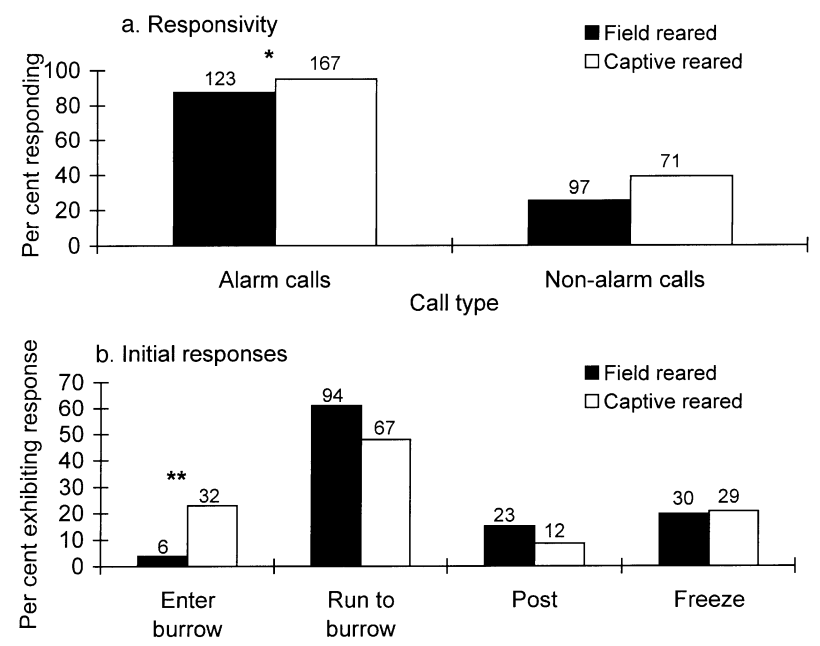

Initial response



Fig. 1: Comparison of responses by field-reared and captive-reared juveniles (Study 2) to playbacks of alarm calls (Spermophilus beldingi whistle chorus, single whistle, and trill) and non-alarm calls (wren song and $S$. beldingi squeal). Data are grouped by call type and all age cohorts are combined. Asterisks represent significant $\left(* * p<0.01,{ }^{*} p<0.05\right)$ differences between groups. See text for details of analyses. a. Proportion of juveniles exhibiting a response to each call type. Numbers above bars represent the total number of responders and non-responders. b. Percentage of field-reared and captive-reared juveniles responding to playbacks with each of four initial-response types. Data from alarm-call and non-alarmcall playbacks are pooled. The numbers above the bars represent the number of times juveniles exhibited that initial-response type. Asterisks represent significant differences between field-born and captive-born juveniles based on partitioned $\chi^{2}(\mathrm{df}=3)$ analyses. c. Juvenile response durations ( $\overline{\mathrm{x}} \pm \mathrm{SE}$ s) measured from presentation of playback until nonalert behaviour was resumed. Data are adjusted for juvenile age 
juveniles remained alert significantly longer than field-reared individuals following both alarm calls and non-alarm calls (ANCOVA $F=27.7$; $\mathrm{df}=1,226 ; \mathrm{p}<0.001$ and $\mathrm{F}=6.51 ; \mathrm{df}=1,53 ; \mathrm{p}<0.05$, respectively; Fig. 1c). Differences in response duration were apparent in both age cohorts (days 1-5 and days 6-15, both $\mathrm{p}<0.05$ ). Finally, field-reared and captive-reared juveniles were equally responsive to aerial-object playbacks (responded on $100 \%$ of 20 and 30 opportunities, respectively) and displayed similar response durations (ANCOVA $F=0.35$; $\mathrm{df}=1,46$; ns) following these stimulus presentations.

\section{Discussion}

Data from the three response measures mirrored the differences originally observed between juveniles reared and observed in captivity and those reared and observed in the field (Mateo \& Holmes 1999). In Study 2, captive-reared juveniles were more likely to respond to both alarm- and non-alarm-call playbacks and remained alert longer than field-reared juveniles (Fig. 1a, c), even though the postemergent environments (outdoor enclosures) were the same for both groups. The captive-reared juveniles were also more likely to enter a burrow than field-reared juveniles (Fig. 1b), indicating that the tendency of captive-housed juveniles to submerge (e.g. Mateo \& Holmes 1999) may not have been due to the proximity or availability of burrows in captivity, but to the juveniles' pre-emergent rearing histories. Response differences to auditory cues did not generalize to overhead visual stimuli (frisbee paired with an alarm-call playback). Further, captive pups did not respond to alarm calls prior to emergence (Mateo 1995), suggesting that an early opportunity to practice responses was not responsible for the heightened responsivity and vigilant postures of captive juveniles after emergence. Collectively, the differences in alarm-call response behaviour of captive-reared and field-reared juveniles reported in Mateo \& Holmes (1999) appear to be largely due to experiences prior to the pups' natal emergence.

We do not know all the ways in which the pre-emergent environments differed for captive- and field-reared young, but we know that captive-reared pups received more stimulation than the field-reared young, including more frequent auditory, visual and tactile input and thermal irregularities, which could have had a number of effects on their development (Daly 1973). In particular, captive-reared young experienced much more conspecific and ambient auditory stimulation than fieldreared young. To characterize the auditory environment of captive-reared pups, which were housed with about 25 litters in the nursery, we recorded the total number of vocalizations (chirps, trills, whistles; Leger et al. 1984) heard in the nursery during 20 arbitrarily chosen $1 \mathrm{~h}$ intervals. Mothers and older juveniles emitted $13.3 \pm 4.4$ vocalizations/h. In contrast, three litters housed in another building emitted only $5.2 \pm 2.5$ vocalizations/h (Mateo 1996a). Clearly, field-reared pups experienced much less auditory stimulation than captive-reared pups, which may have had behavioural consequences (Denenberg et al. 1966; Daly 1973). However, extensive exposure to alarm calls during the pre-emergent period did not habituate the young to the calls, as captive-reared juveniles tended to be hyper- 
responsive to playbacks after emergence. Finally, captive mothers may have been affected by our frequent handling and daily presence during late gestation and lactation, which could have influenced the response phenotypes of their offspring (e.g. Archer \& Blackman 1971; Gandelman 1992).

\section{General Discussion}

Belding's ground squirrels reared and observed in captivity are more responsive to playbacks of both alarm calls and non-alarm calls, maintain alert behaviour longer following playbacks, and are more likely to run to a refuge after a playback than ground squirrels reared and observed in the field (Mateo \& Holmes 1999). Based on our results in Study 2 (Fig. 1a-c), we suggest that these differences in alarm-call response behaviour patterns are due primarily to pre-emergent rather than post-emergent differences in the environments experienced by free-living and captive young, because when we observed field-reared young in an outdoor enclosure, their responses to alarm-call playbacks mirrored those of free-living young that remained in the field. The pre-emergent environments of free-living and captive young differed in many ways, including the quality and quantity of both speciesspecific and non-specific auditory, visual, and tactile stimulation present in the environments during the pups' prenatal development and the $25-28 \mathrm{~d}$ postnatal period when the pups resided in their natal burrow before emerging above ground.

The results of our two series of studies demonstrate that the ontogeny of behaviour can differ as a function of a developing animal's early rearing environment even when the behaviour is as critical to survival as antipredator behaviour, which some researchers have suggested emerges more or less independently of early experience (reviewed by Curio 1993). 'Species-typical' behaviours refer only to outcomes of development throughout the range of a species' environments. The process by which these behaviours emerge is not predetermined or innate, but instead depends on a multitude of interactions between developing individuals and the environments they encounter (e.g. Mateo 1996b; see Mateo \& Holmes 1997, 1999 for further discussion of processes and outcomes in behavioural development). The influence of early experience, including the effects of non-obvious stimuli (Gottlieb 1981), is often overlooked or under-appreciated in developmental studies (Michel \& Moore 1995), but can have important theoretical (e.g. Miller 1981, 1994; West \& King 1987) and practical implications (e.g. reintroduction programmes; Kleiman et al. 1986; Miller et al. 1994).

\section{Developmental Consequences of Early Stimulation}

The quantity, quality, and timing of stimulation during early postnatal development, even before a predator is first encountered, may influence the development of species-typical antipredator behaviour. For instance, experiential enhancement, stimulation of specific modalities at greater-than-species-typical levels during development (Miller 1981), can lead to subsequent increased responsiveness by those modalities (e.g. Rydén 1978; Jones 1982; Lickliter 1995). Thus, captive S. beldingi 
juveniles may have developed heightened alarm-call responses simply because as pups they experienced more frequent auditory, olfactory, visual, and/or tactile stimulation than field-reared pups rather than because of a specific kind of stimulation associated directly with alarm calls (see also Clark \& Galef 1980, 1982). Alternatively, the timing, rather than the quantity or quality, of stimulation may modulate alarm-call response development (Turkewitz \& Kenny 1982; Lickliter 1995), much as it influences the development of bird song (Marler 1987) and filial preferences (Bolhuis 1991). Differences between prenatal auditory and/or tactile stimulation may help explain the free-living vs. captive juvenile differences found, in addition to or independent of postnatal differences in stimulation (Smotherman \& Robinson 1988). Levels of stimulation before hatching or birth, but not during later periods, can sometimes affect how animals respond to subsequent stimulation (e.g. Denenberg et al. 1966; Miller \& Blaich 1984).

By emphasizing pre-emergent effects on alarm-call response development, we do not mean to imply that later experience plays little or no role in the ontogeny of antipredator behaviour. For example, in various species of fishes and birds, experience with predators, with predator-experienced parents, with agonistic adult conspecifics, or with alarm calls affects later responses to predator cues (Impekoven 1976; Vince 1980; Goodey \& Liley 1986; Tulley \& Huntingford 1987; Magurran 1990). And we know that the development of the response repertoires of $S$. belding $i$ juveniles to alarm calls is affected by their post-emergent experiences, including interactions with predators and alarm call experienced adults (Mateo 1995; Mateo \& Holmes 1997).

Because the responses of captive and free-living juveniles to auditory but not audiovisual stimuli differed (Mateo \& Holmes 1999; see also Study 2), the salient pre-emergent stimulus responsible for these phenotypic differences may also have been auditory (but see Turkewitz \& Kenny 1982; references in Lickliter 1995). Captive pups were exposed to more conspecific vocalizations than free-living young, yet it is unclear whether specific exposure to alarm calls or to ambient auditory stimulation (e.g. electric fans, rattling cages and water bottles, human voices), both of which were greater in the nursery than in the field, affected the expression of responses to auditory signals (Denenberg et al. 1966; Daly 1973). Captive juveniles were more responsive to all auditory stimuli, including nonthreatening calls, and they developed a discrimination between alarm and nonalarm calls 1 or $2 \mathrm{~d}$ later than free-living juveniles (Fig. 2 of Mateo \& Holmes 1999), suggesting that non-specific auditory stimulation, rather than exposure to particular vocalizations, may mediate response development. Future studies will seek to determine the amount of auditory stimulation free-living pups are exposed to in their natal burrows, and examine the relative influences of specific and general stimulation prior to emergence on post-emergent responsivity.

\section{Function of Sensitivity to Early Experiences}

One function of $S$. beldingi pups' sensitivity to their early rearing environment may be to prepare newly emergent juveniles for differences in predation risk that 
different local environments pose, which could arise from the number or types of predators in a particular environment and/or from features of the physical environment itself that render juveniles more or less vulnerable to predators (see also Impekoven (1976), Vince (1980), Goodey \& Liley (1986), Lagory (1986), Tulley \& Huntingford (1987), Hauser (1988), Magurran (1990) and Mateo (1995)). For example, we heard alarm calls at least twice as often in one S. belding $i$ population as in another we studied, even though we saw aerial and terrestrial predators at similar rates at each site (pers. obs.). The physical environment of the frequent-calling population is characterized by low visibility (and perhaps poor acoustic transmission) due to mountains, trees and bushes, whereas the local environment of the infrequent-calling population is visually open, which allows ground squirrels to detect predators and escape routes at a distance. In both populations, we saw the heads of soon-to-emerge pups at the entrance to their natal burrow a few days before they came fully above ground. Thus, pups in a frequent-calling population may hear frequent alarm calls before their actual natal emergence, and thus be more responsive to alarm calls shortly after their natal emergence, relative to pups developing in an infrequent-calling population. Preemergent sensitivity to experience could also prepare newly emergent juveniles in low-predation risk environments for reduced levels of vigilance or responsivity to auditory stimuli. Excessive vigilance can interfere with energy intake in juvenile $S$. beldingi (Bachman 1993), which could hinder over-winter survival (Murie \& Boag 1984). Thus, the selective advantage of pre-emergent priming may be the rapid development of locally appropriate responses to auditory stimuli, including alarm calls, and consequently an increased probability of escape by newly emergent juveniles that are especially susceptible to predation (Sherman 1976; Mateo 1996b). Our results therefore suggest a causal link between the pre-emergent environment of $S$. beldingi and their expression of species-typical alarm-call response behaviour.

\section{Acknowledgements}

This research was supported by a National Science Foundation Dissertation Improvement Grant (IBN-9311508) as well as funding from Sigma Xi, American Society of Mammalogists and Rackham School of Graduate Studies to JMM and National Institute of Mental Health (MH 43861) and the University of Michigan's Office of the Vice President of Research to WGH. We thank A. Bell, M. Clancy, J. Osborn and L. Starr for their assistance in collecting the data, D. Leger for sharing his collection of $S$. beldingi alarm-call recordings with us, D. Dawson, director of SNARL, for his encouragement and co-operation, and G. Gerstner, R. Johnston, T. Lee, J. Mitani, B. Smuts and two reviewers for comments on previous versions of the manuscript.

\section{Literature Cited}

Archer, J. C. \& Blackman, D. E. 1971: Prenatal psychological stress and offspring behavior in rats and mice. Dev. Psychobiol. 4, 193-248.

Bachman, G. C. 1993: The effect of body condition on the trade-off between vigilance and foraging in Belding's ground squirrels. Anim. Behav. 46, 233-244.

Bolhuis, J. J. 1991: Mechanisms of avian imprinting: a review. Biol. Rev. 66, 303-345.

Brown, M. M., Kreiter, N. A., Maple, J. T. \& Sinnott, J. M. 1992: Silhouettes elicit alarm calls from captive vervet monkeys (Cercopithecus aethiops). J. Comp. Psychol. 106, 350-359. 
Brown, C. H. \& Schwagmeyer, P. L. 1984: The vocal range of alarm calls in thirteen-lined ground squirrels. Z. Tierpsychol. 65, 273-288.

Clark, M. M. \& Galef, B. G. Jr. 1980: Effects of environment on adrenal weights, sexual development, and behavior in gerbils: an examination of Richter's domestication hypothesis. J. Comp. Physiol. Psychol. 94, 857-863.

Clark, M. M. \& Galef, B. G. Jr. 1982: Environmental effects on the ontogeny of exploratory and escape behaviors of Mongolian gerbils. Dev. Psychobiol. 15, 121-129.

Curio, E. 1993: Proximate and developmental aspects of antipredator behavior. In: Advances in the Study of Behavior, Vol. 22 (Slater, P. J. B., Rosenblatt, J. S., Snowdon, C. T. \& Milinski, M., eds). Academic Press, New York, pp. 135-238.

Daly, M. 1973: Early stimulation of rodents: a critical review of present interpretations. Br. J. Psychol. 64, $435-460$.

Denenberg, V. H., Schell, S. F., Karas, G. G. \& Haltmeyer, G. C. 1966: Comparison of background stimulation and handling as forms of infantile stimulation. Psychol. Rep. 19, 943 — 948.

Elgar, M. A. 1989: Predator vigilance and group size in mammals and birds: a critical review of the empirical evidence. Biol. Rev. 64, 13-33.

Gandelman, R. 1992: Psychobiology of Behavioral Development. Oxford Univ. Press, New York.

Goodey, W. \& Liley, N. R. 1986: The influence of early experience on escape behaviour in the guppy. Can. J. Zool. 64, 885-888.

Gottlieb, G. 1981: Roles of early experience in species-specific perceptual development. In: Development of Perception, Vol. 1 (Aslin, R. N., Alberts, J. R. \& Petersen, M. R., eds). Academic Press, New York, pp. 5-44.

Hauser, M. D. 1988: How infant vervet monkeys learn to recognize starling alarm calls: the role of experience. Behaviour 105, 187-201.

Holmes, W. G. 1984: Predation risk and foraging behavior of the hoary marmot in Alaska. Behav. Ecol. Sociobiol. 15, 293-301.

Holmes, W. G. 1994: The development of littermate preferences in juvenile Belding's ground squirrels. Anim. Behav. 48, 1071-1084.

Hoogland, J. L. 1995: The Black-tailed Prairie Dog: Social Life of a Burrowing Mammal. Univ. of Chicago Press, Chicago.

Impekoven, M. 1976: Responses of laughing gull chicks (Larus atricilla) to parental attraction- and alarm-calls, and effects of prenatal auditory experience on the responsiveness to such calls. Behaviour 56, $250-277$.

Jones, R. B. 1982: Effects of early environmental enrichment upon open-field behavior and timidity in the domestic chick. Dev. Psychobiol. 15, 105-111.

Kleiman, D. G., Beck, B. B., Dietz, J. M., Dietz, L. A., Ballou, J. D. \& Coimbra-Filho, A. F. 1986: Conservation program for the golden lion tamarin: captive research and management, ecological studies, educational strategies and reintroduction. In: Primates: The Road to Self-sustaining Populations (Benirschke, K., ed.). Springer, New York, pp. 959—979.

Lagory, K. E. 1986: Habitat, group size, and the behaviour of white-tailed deer. Behaviour 98, 168-179.

Lazarus, J. \& Symonds, M. 1992: Contrasting effects of protective and obstructive cover on avian vigilance. Anim. Behav. 43, 519-521.

Leger, D. W., Berney-Key, S. D. \& Sherman, P. W. 1984: Vocalizations of Belding's ground squirrels (Spermophilus beldingi). Anim. Behav. 32, 753-764.

Leger, D. W., Owings, D. H. \& Coss, R. G. 1983: Behavioral ecology of time allocation in California ground squirrels (Spermophilus beecheyi): microhabitat effects. J. Comp. Psychol. 97, 283-291.

Lickliter, R. 1995: Embryonic sensory experience and intersensory development in precocial birds. In: Fetal Development: A Psychobiological Perspective (Lecanuet, J.-P., Fifer, W. P., Krasnegor, N. A. \& Smotherman, W. P., eds). Lawrence Erlbaum Assoc., Hillsdale, pp. 281-294.

Lima, S. L. 1987: Distance to cover, visual obstructions, and vigilance in house sparrows. Behaviour 102, 231-238.

Lima, S. L. \& Dill, L. M. 1990: Behavioral decisions made under the risk of predation: a review and prospectus. Can. J. Zool. 68, 618-640.

MacHutchon, A. G. \& Harestad, A. S. 1990: Vigilance behaviour and use of rocks by Columbian ground squirrels. Can. J. Zool. 68, 1428-1432.

Magurran, A. E. 1990: The inheritance and development of minnow anti-predator behaviour. Anim. Behav. 39, $834-842$. 
Marler, P. 1987: Sensitive periods and the roles of specific and general sensory stimulation in birdsong learning. In: Imprinting and Cortical Plasticity (Rauschecker, J. P. \& Marler, P., eds). Wiley \& Sons, New York, pp. 99-135.

Mateo, J. M. 1995: The development of alarm-call responses in free-living and captive Belding's ground squirrels, Spermophilus beldingi. PhD Diss., Univ. of Michigan, Ann Arbor.

Mateo, J. M. 1996a: Early auditory experience and the ontogeny of alarm-call discrimination in Belding's ground squirrels (Spermophilus beldingi). J. Comp. Psychol. 110, 115-124.

Mateo, J. M. 1996b: The development of alarm-call response behaviour in free-living juvenile Belding's ground squirrels. Anim. Behav. 52, 489-505.

Mateo, J. M. \& Holmes, W. G. 1997: Development of alarm-call response behaviour in juvenile Belding's ground squirrels: the role of dams. Anim. Behav. 54, 509-524.

Mateo, J. M. \& Holmes, W. G. 1999: Plasticity of alarm-call response development in Belding's ground squirrels (Spermophilus beldingi, Sciuridae). Ethology 105, 193-206.

Michel, G. F. \& Moore, C. L. 1995: Developmental Psychobiology. MIT Press, Cambridge.

Miller, B., Biggins, D., Hanebury, L. \& Vargas, A. 1994: Reintroduction of the black-footed ferret (Mustela nigripes). In: Creative Conservation: Interactive Management of Wild and Captive Animals (Olney, P. J. S., Mace, G. M. \& Feistner, A. T. C., eds). Chapman \& Hall, London, pp. 455-464.

Miller, D. B. 1981: Conceptual strategies in behavioral development: normal development and plasticity. In: Behavioral Development (Immelmann, K., Barlow, G. W., Petrinovich, L. \& Main, M., eds). Cambridge Univ. Press, New York, pp. 58-85.

Miller, D. B. 1994: Social context affects the ontogeny of instinctive behaviour. Anim. Behav. 48, 627634.

Miller, D. B. \& Blaich, C. F. 1984: Alarm call responsivity of mallard ducklings: the inadequacy of learning and genetic explanation of instinctive behavior. Learn. Motiv. 15, 417 — 427.

Morton, M. L. 1975: Seasonal cycles of body weights and lipids in Belding's ground squirrels. Bull. S. California Acad. Sci. 74, 128-143.

Murie, J. O. \& Boag, D. A. 1984: The relationship of body weight to overwinter survival in Columbian ground squirrels. J. Mamm. 65, 688-690.

Owings, D. H. \& Virginia, R. A. 1978: Alarm calls of California ground squirrels (Spermophilus beecheyi). Z. Tierpsychol. 46, 58-70.

Poran, N. S. \& Coss, R. G. 1990: Development of antisnake defenses in California ground squirrels (Spermophilus beecheyi): I. Behavioral and immunological relationships. Behaviour 112, 222-245.

Robinson, S. R. 1980: Antipredator behaviour and predator recognition in Belding's ground squirrels. Anim. Behav. 28, 840-852.

Robinson, S. R. 1981: Alarm communication in Belding's ground squirrels. Z. Tierpsychol. 56, 150-168.

Rydén, O. O. 1978: The significance of antecedent auditory experiences on later reactions to the 'seeet' alarm-call in great tit nestlings Parus major. Z. Tierpsychol. 47, 396-409.

Sherman, P. W. 1976: Natural selection among some group-living organisms. PhD Diss., Univ. of Michigan, Ann Arbor.

Sherman, P. W. 1977: Nepotism and the evolution of alarm calls. Science 197, 1246-1253.

Sherman, P. W. 1985: Alarm calls of Belding's ground squirrels to aerial predators: nepotism or selfpreservation? Behav. Ecol. Sociobiol. 17, 313-323.

Sherman, P. W. \& Morton, M. L. 1984: Demography of Belding's ground squirrels. Ecology 65, 16171628.

Smotherman, W. P. \& Robinson, S. R. (eds) 1988: Behavior of the Fetus. Telford Press, Caldwell.

Tulley, J. J. \& Huntingford, F. A. 1987: Parental care and the development of adaptive variation in anti-predator responses in sticklebacks. Anim. Behav. 35, 1570-1572.

Turkewitz, G. \& Kenny, P. A. 1982: Limitations on input as a basis for neural organization and perceptual development: a preliminary theoretical statement. Dev. Psychobiol. 15, 357-368.

Vince, M. A. 1980: The posthatching consequences of prehatching stimulation: changes with amount of prehatching and posthatching exposure. Behaviour 75, 36-53.

West, M. J. \& King, A. P. 1987: Settling nature and nurture into an ontogenetic niche. Dev. Psychobiol. 20, 549-562.

Received: December 17, 1997

Initial acceptance: July 24, 1998

Final acceptance: September 4, 1998 (J. Brockmann) 